\title{
A living system for future engineers
}

\author{
K. Jahan ${ }^{1}$, J. W. Everett ${ }^{1}$, S. Farrell ${ }^{2}$, G. Tang ${ }^{3}$, H. Zhang ${ }^{4}$, \\ A. Wenger ${ }^{5} \&$ M. Noorie ${ }^{6}$ \\ ${ }^{1}$ Department of Civil and Environmental Engineering, \\ Rowan University, USA \\ ${ }^{2}$ Department of Chemical Engineering, Rowan University, USA \\ ${ }^{3}$ Department of Electrical and Computer Engineering, \\ Rowan University, USA \\ ${ }^{4}$ Department of Mechanical Engineering, Rowan University, USA \\ ${ }^{5}$ New Jersey Academy for Aquatic Sciences, USA \\ ${ }^{6}$ Cumberland County College, USA
}

\begin{abstract}
Engineering education needs to be attractive, relevant and practical to attract talented individuals to the profession. Using a known fun living system can bring engineering alive as a viable career option. An aquarium is a great example of a living system that can be used as a teaching tool for future engineers. It is an exquisite combination of live interacting systems which can be analyzed using multidisciplinary engineering and science principles. While children are familiar with an aquarium via personal aquariums or school field trips to a commercial aquarium, they seldom make a connection to the engineering and science principles behind the design, operation and maintenance of such a living system. Students can easily be introduced to different engineering topics, principles and disciplines via the study of such a system. Common topics such as mass and energy balances; fluid flow; work, energy, and efficiency; forces and levers; material strength and stresses; water quality and treatment; and electrical signal processing can be made relevant to the workings of a living system. The aquarium theme also adds to the need for an understanding of biological systems, ecosystems, pollution and sustainable development. This paper describes the use of a living system such as an aquarium to teach science and engineering concepts to students of all ages.
\end{abstract}

Keywords: aquarium, sustainability, water quality, materials, living system. 


\section{Introduction}

Educators are always challenged to develop new exciting teaching tools to engage students' imagination and provide a platform for integrating cutting edge technology into the undergraduate science and engineering curricula. Typically students like to learn from familiar systems. The aquarium idea is creative and innovative because it is a known system. It is also truly multidisciplinary.

The living system aquarium project is an innovative initiative between three institutions located in New Jersey, USA: the College of Engineering at Rowan University, Cumberland County College (CCC) and the New Jersey Academy of Aquatic Sciences (NJAAS). The purpose of the initiative is to enhance STEM (Science, Technology, Engineering, Mathematics) education at all levels. This project uses an aquarium to enhance the delivery of STEM education to a wide audience. Partnership with CCC allows them to offer an introductory engineering course that will easily transfer to the Rowan Engineering program while the partnership with NJAAS allows K-12 education in aquatic sciences to be connected to engineering.

The broad educational goals of this project are to:

- $\quad$ ensure the highest quality STEM education;

- $\quad$ increase participation of underrepresented students and ensure a high level of student retention in STEM areas by introducing science and engineering principles via a familiar system such as an aquarium; and

- develop multidisciplinary curricula.

There is a growing realization among science and engineering faculty that a new method of delivery for the education of engineers needs to be developed to keep the USA at the forefront of global technology. Science and engineering are essential for paving the way for America's future through discovery, learning and innovation [1]. A recent report [2-3] indicates that the United States lags behind the world in technological innovation because of its poor performance in teaching math and science. Better preparation of students in the K-12 system needs to be integrated so that students are prepared and excited about engineering careers. Enhanced engineering education in our K-12 classrooms can provide students at an earlier age with a more specific understanding of what a technical career entails.

The College of Engineering at Rowan University is always seeking innovative teaching methods to excite freshman engineering students about engineering design [4-16]. The aquarium project was selected to expose K-12 students/educators and freshman students in engineering at Rowan, CCC [17] and NJAAS [18]. Students can easily be introduced to chemical, mechanical, electrical engineering, civil and environmental principles such as mass and energy balances; fluid flow; work, energy, and efficiency; forces and levers; material strength and stresses; water quality and treatment; and electrical signal processing. The aquarium theme also adds to the need for an understanding of biological systems, ecosystems, pollution and sustainable development. These are concepts that have been absent in typical traditional engineering concepts. 


\section{Materials and methods}

The living system project consists of the following components:

a) Development of hands on activities for students of all ages that are relevant to a living system like an aquarium,

b) Providing remote water quality data and real-time images for a marine aquarium located at the NJAAS using the World Wide Web, and

c) Use of the developed activities to enhance STEM education at all levels.

Hands on activities relevant to an aquarium were developed such that the activities were simple, cost-effective and easy to implement. Most of the materials used for developing experiments were typically purchased from either pet or laboratory supplies stores.

A 250 gallon marine aquarium at NJAAS was fitted with an AXIS 2120 Network Camera such that real-time images of the fish in the aquarium can be seen on the project website. The aquarium was also instrumented with water quality sensors to monitor $\mathrm{pH}$, temperature, conductivity, ORP and dissolved oxygen with time. The data from these sensors are also available real-time at the project website. An Aqua Controller III Pro water quality monitoring system was used for component of the project. The aquarium is host to a number of fish species (such as clown fish, tang, and angel fish), corals and invertebrates.

The instrumented aquarium is presented in Figure 1.

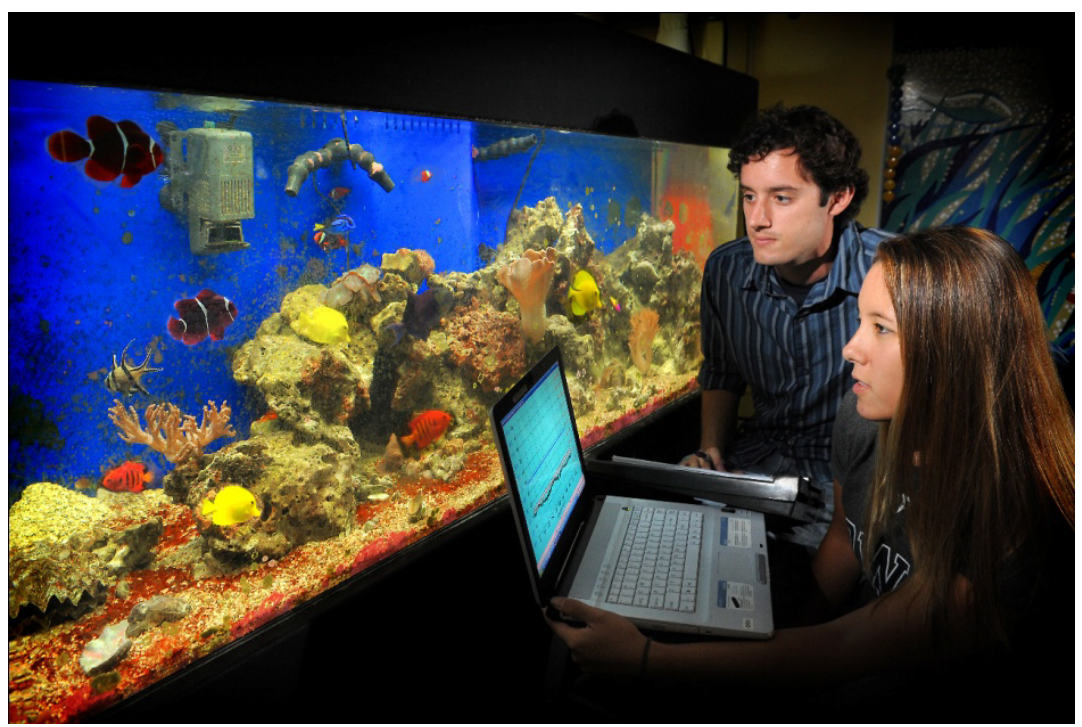

Figure 1: Water quality data collection at the NJAAS for the marine aquarium. 


\section{Results and discussion}

An engineering freshman class both at Rowan University and CCC were introduced to the science and engineering behind the design, operation and maintenance of an aquarium. Students were exposed to engineering principles via hands on activities over a fourteen week period. Experimental modules included the following:

- Water Quality Testing

- Gas Transfer-Aeration

- Gas Transfer-Respiration

- Material Testing

- Hydraulics

- Heat Transfer

- Thermo-Image Analysis

- Water Treatment Processes

- Toxicity of Pollutants to Aquatic Organisms

- Environmental Ethics

- Data Acquisition and Remote Control

- WWW and Networking

A sample description of the fish respiration module is provided below:

Fish are a coldblooded species that thrive in warmer waters. They require a minimum concentration of dissolved oxygen (DO) in water between 5 and 7 ppm to survive. This concentration can prove difficult to maintain because gas becomes less soluble as the temperature of the water increases. Aeration of lakes and ponds occur naturally by diffusion at the surface of the water, photosynthesis of microorganisms and plants, and wind and wave action. Although indoor aquariums may be open to air at the surface and contain plants to generate oxygen, this alone is not nearly enough, and aquariums require aeration in order to replenish and maintain dissolved oxygen consumed by fish. An unsteady state mass balance on the dissolved oxygen concentration is shown below:

$$
V \frac{d c_{D O}}{d t}=\dot{n}_{D O_{i}}-\dot{n}_{D O}+G_{D O}
$$

The left side of this mass balance represents the change moles of oxygen with respect to time. The right side is equal to the molar flow rate of oxygen into the aquarium minus the molar flow rate out of the aquarium plus the rate of oxygen generated (or consumed).

A laboratory experiment was developed to study the rate of respiration of fish under different environmental conditions such as temperature, ammonia level, and $\mathrm{pH}$. For each environmental condition, the rate of respiration was determined in a closed tank with no aeration. The level of DO was closely 


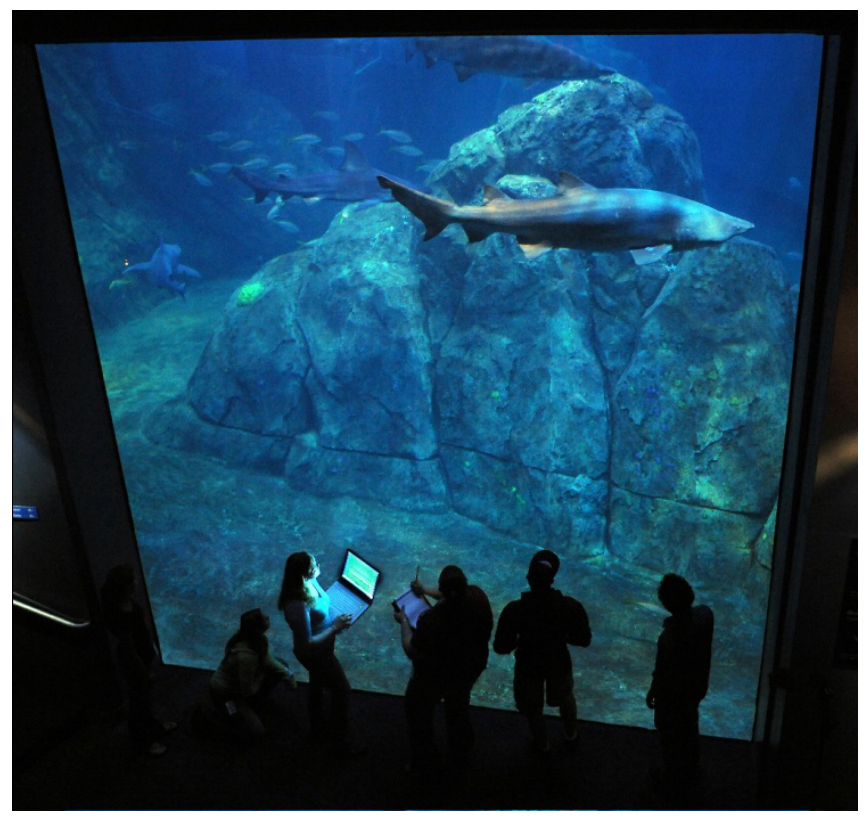

Figure 2: Students working on the project at the aquarium.

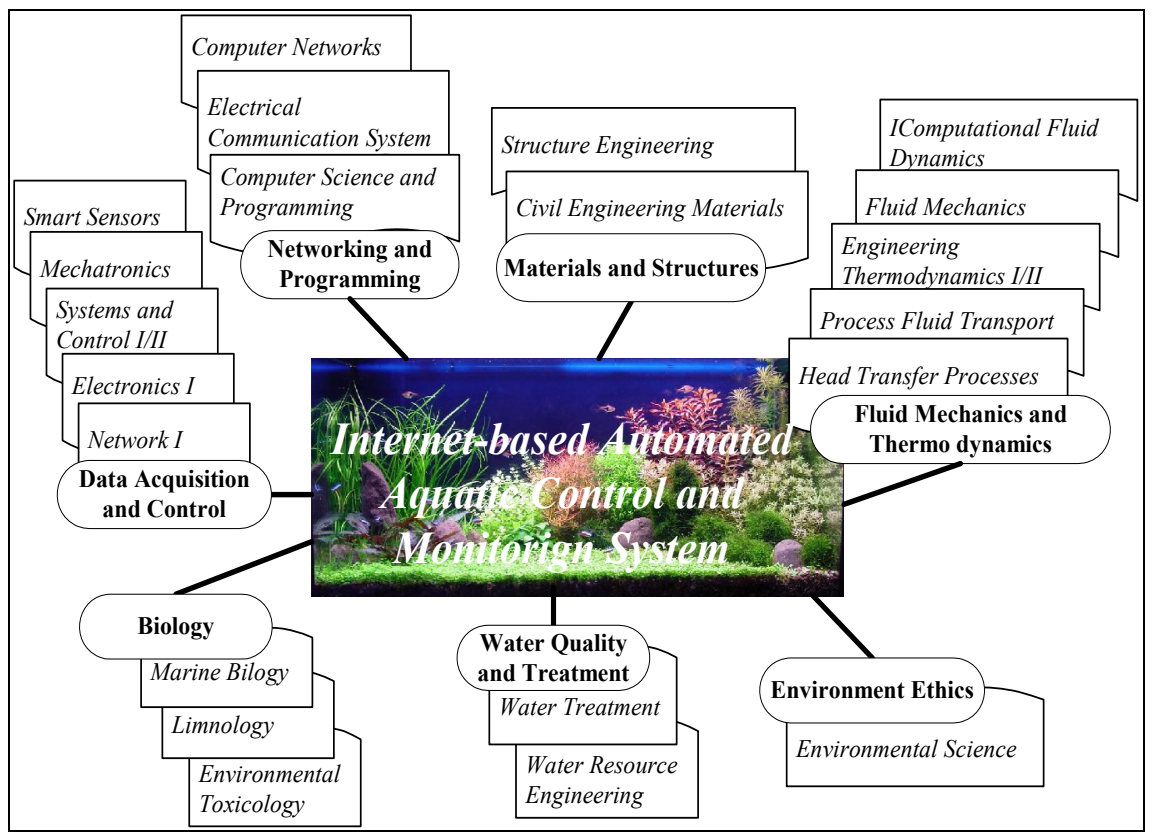

Figure 3: Courses that can be impacted by the project. 
monitored to be sure that the concentration did not drop low enough to cause harm to the fish. The experiment was repeated with different levels of aeration to study the effect of aeration on the level of DO in the tank.

A dynamic website [19] has been set up to disseminate the project. The website includes images as shown in Figure 2, water quality data, real-time aquarium images, lecture notes, video clips on experiments, experimental handouts and also a virtual aquarium for assisting children to learn about science and engineering as it is relevant to a living system.

The activities from this project are also used for K-12 outreach and teacher workshops. Many schools across the country have classrooms with aquariums. As such the material developed is very useful to teachers that already have a living system in their schools. Schools that do not have access to a living system and cannot afford the travel expenses can use the online aquarium for teaching purposes through the World Wide Web.

Many courses in the science and engineering curriculum can also be impacted by the experimental modules developed for this project. These courses are presented in Figure 3.

\section{Conclusions}

This paper has focused on how a living system such as an aquarium can be used to teaching science and engineering principles to a wide group of students. The proposed modules expose a broad audience (K-12 students and teachers, science and two year county/engineering college students and faculty) to multidisciplinary engineering and science principles using hands-on simple experiments with data acquisition. The most important exciting feature is the dynamic website showcasing the real time data and images of the aquarium. Posting of the real time data and images on the website allows schools and colleges to explore an aquarium without the expense of setting up their own. Experimental details, laboratory manuals, course materials such as problems and lecture slides, are posted on the website for easy access by schools, colleges and other state aquariums. The location of NJAAS and CCC in Federal Empowerment Zones allows large numbers of students from underrepresented populations to be exposed to engineering concepts. Rowan and NJAAS mentoring programs for K-12 educators and students allow aggressive dissemination. Finally, the theme provides an opportunity for students to work on use of state-of-the-art technology on a real live system that will foster their interests in sustainability, ethics and pollution prevention.

\section{Acknowledgement}

This project is being funded by the National Science Foundation (DUE0737277). Any opinions, findings and conclusions or recommendations expressed in this material are those of the author(s) and do not necessarily reflect the views of the National Science Foundation (NSF). 


\section{References}

[1] http://www.nsf.gov

[2] http://www.engineeringk12.org/Engineering_in_the_K-12_Classroom.pdf

[3] http://www.nae.edu/nae/naehome.nsf

[4] Jahan, K., Hesketh, R. P., Schmalzel, J. L. and Marchese, A. J. (2001). Design and Research Across the Curriculum: The Rowan Engineering Clinics. International Conference on Engineering Education. August, $6-$ 10, 2001 Oslo, Norway

[5] Harvey, R., Johnson, F., Marchese, A. J., Newell, J. A., Ramachandran, R. P., and Sukumaran, B. (1999). Improving the Engineering and Writing Interface: An Assessment of a Team-Taught Integrated Course. ASEE Annual Meeting, St. Louis, MO.

[6] R.P. Hesketh, S. Farrell, and C.S. Slater, An Inductive Approach to Teaching Courses in Engineering, 2003 ASEE Annual Conference, Session 2531, June 2003.

[7] Schmalzel, J. L., Marchese, A. J., Mariappan, J., and Mandayam, S. (1998). The Engineering Clinic: A Four-Year Design Sequence. 2nd Annual Conference of National Collegiate Inventors and Innovators Alliance, Washington, DC.

[8] Hesketh, R. P., Jahan, K., Marchese, A. J. (1997) Integrating Hands-on Education to Freshman Engineers at Rowan College. 1997 ASEE Zone 1 Spring Meeting. West Point, NY, April, 1997.

[9] Hesketh, R. P., Jahan, K., Marchese, A. J. (1997) Integrating Hands-on Education to Freshman Engineers at Rowan College. 1997 ASEE Zone 1 Spring Meeting. West Point, NY, April, 1997.

[10] Hesketh, R. P., Jahan, K., Marchese, A. J. (1997) Integrating Hands-on Education to Freshman Engineers at Rowan College. 1997 ASEE Zone 1 Spring Meeting. West Point, NY, April, 1997.

[11] K. Jahan and R.A. Dusseau, "Teaching Civil Engineering Measurements through Bridges", Proceedings of the 1998 Annual Conference of ASEE, Seattle, Washington, June, 1998.

[12] K. Jahan, Marchese, A. J., Hesketh, R.P., C.S. Slater, J.L. Schmalzel, T.R. Chandrupatla and R.A. Dusseau, "Engineering Measurements and Instrumentation for a Freshman Class ", Proceedings of the 1998 Annual Conference of ASEE, Seattle, Washington, June, 1998.

[13] K. Jahan and R.A. Dusseau, "Water Treatment through Reverse Engineering", Proceedings of the Middle Atlantic Section Fall 1998 Regional Conference, Washington D.C., November 6-7, 1998.

[14] Ramachandran R. P., Schmazel, J., and Mandayam, S., "Engineering Principles of an Electric Toothbrush," ASEE annual conference and Exhibition, Charlotte, North Carolina, Session 2253, June 20-23, 1999.

[15] Marchese, A. J., Ramachandran, R. P., Hesketh, R., Schmalzel, J., and Newell, H. L., "The competitive assessment laboratory: Introducing Engineering Design via Consumer Product Benchmarking," IEEE Transaction on Education, Vol. 46, No. 1, 2003, pp. 197-205. 
544 Design and Nature V

[16] Everett, J., J. Chen, S. Farrell, J. Kadlowec (2008) “Clickers and Freshman Engineering Clinic,” 2008 ASEE Annual \& Exposition, Pittsburg, PA.

[17] http://www.njaquarium.org/index 2.html

[18] http://www.cccnj.edu/

[19] http://elvis.rowan.edu/rquarium/ 